\title{
N3a Stage Finding
}

National Cancer Institute

\section{Source}

National Cancer Institute. N3a Stage Finding. NCI Thesaurus. Code C48715.

A general term that refers to a TNM finding of cancer metastases in multiple lymph nodes. The definition of N3a TNM finding depends on the specific type of cancer that it refers to; for example, for breast cancer it refers to metastases in 10 or more axillary lymph nodes (at least one tumor deposit greater than $2.0 \mathrm{~mm}$ ) or metastases to the infraclavicular (level III axillary) lymph nodes; for gastric cancer it refers to metastases in 7-15 regional lymph nodes; for nasopharyngeal cancer it refers to metastases to one or more lymph nodes greater than $6 \mathrm{~cm}$ in greatest dimension. 